\title{
Die eskatologiese betekenis van Sion as agtergrond tot die teologie van die boek Openbaring
}

J A du Rand

\section{ABSTRACT}

The eschatological meaning of Sion as background to the theology of the book of Revelation

The core of the theology of the Book of Revelation focuses on the kingship of God. His kingship should be established on earth as it is in heaven. According to the Old Testament eschatological traditions God's kingship is linked with the Davidic dynasty by way of application. And the Davidic kingship is very much focused on Sion and Jerusalem. Through a theological review of the Old Testament meaning of the place and function of Sion within eschatology, linked up with God's kingship, a necessary background for the theology of the Book of Revelation is sketched.

\section{INLEIDEND}

Die teologie volgens die boek Openbaring fokus eerder op die godsleer as op 'n eensydige christologie. En spesifiek op die koningskap van God. Die ontplooiing van sy koningskap op aarde, soos wat dit reeds in die hemel bestaan, gee dinamiek aan die narratief van Openbaring. Sodanige koningskapsteologie het 'n wydvertakte verstaansagtergrond wat ten nouste saamhang met die teologie volgens die Ou Testament. God se koningskap en eskatologie volgens die Ou-Testamentiese tradisies kan by wyse van teologiese interpretasie verbind word aan die Dawidshuis wat weer op sy beurt ' $n$ noue verbintenis het met die berg Sion en Jerusalem. Laasgenoemde neem 'n sentrale plek in die eskatologiese tradisies van Israel in. Die koningskap van God as teologiese fokusmoment in die boodskap van Openbaring kan dus eers behoorlik verstaan en uitgewerk word nadat die eskatologiese rol en funksie van Sion verreken is. God se koningskap word trouens eers volmaak erken en beleef in die nuwe Jerusalem volgens Openbaring. In die nuwe Jerusalem, op die berg Sion, kulmineer die eskatologiese verwagtinge van Israel asook diê van die kerk. Daarom lê die verstaan van die verband tussen Sion, Jerusalem, eskatologie en die koningskap van God nie net op geografiese of mitologiese terrein nie, maar veral op die gebied van historiese, en spesifiek eskatologiese besinning. 
Om nie eers te praat van die apokaliptiese trefwydte van die eskatologiese betekenis van Sion nie.

\section{OPENBARING 14:1}

As vertrekpunt van die ondersoek word eerstens kennis geneem van Openbaring 14:1: "Toe het ek die Lam op Sionsberg sien staan en by Hom

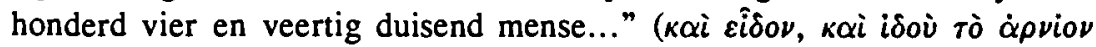

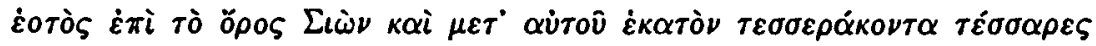
$\chi(\lambda \iota \alpha \dot{\delta} \varepsilon \varsigma)^{1}$. Na die dinamiese beskrywing van die vreesaanjaende draak en diere uit die see en aarde in die voorafgaande hoofstukke 12-13, gee die verteller eers weer 'n perspektief van hoop in hoofstuk 14. Die nuwe daeraad van finale verlossing breek aan met die Lam en sy volgelinge wat op Sion stelling inneem².

Dié toneel staan in radikale kontras teenoor die dier en sy volgelinge wat die merk 666 dra (vgl 13:16-17). Die volgelinge van die Lam, daarteenoor, dra die naam van die Lam en die Vader op hulle voorkoppe. Dat die oorwinningstoneel juis op Sion voorgestel word, is aangrypend. In 2 Esra vind ons 'n interessante parallel. Esra sien ook op Sion 'n groot skare wat lofliedere sing. In hul midde staan 'n jongman wat krone op die mense se hoofde plaas. Esra vind dan uit dat die jongman die Seun van God is ${ }^{3}$. Die temas van verlossing en heerskappy word by wyse van interpretasie op die voorgrond gestoot deur die krone wat die "jongman" op die skare se hoofde plaas.

Dit is ook teologies veelseggend dat die Lam volgens Openbaring 14:1 op Sion staan. Dit is tradisioneel beskou as die heilige plek waar goddelike verlossing sal aanbreek. Sion is beskou as die lokalisering van God se groot eskatologiese handelinge ${ }^{4}$. Die berg Sion, volgens die visioen in Openbaring 14:1, is egter nie op aarde nie. Dit is volgens alle interpretatiewe moontlikheid die hemelse Sion waarvan sprake is. 'n Mens sou dit die hemelse modeltipe kon noem van die heilige Jerusalem van ouds. Dit bring ons by 'n verdere ondersoek na die algemene betekenis van die berg Sion om uiteindelik by die teologiese eskatologiese funksie daarvan uit te kom.

\section{SION IN ALGEMENE HISTORIESE PERSPEKTIEF}

Die term Sion kom ongeveer 150 keer in die Ou Testament voors . Geografies kan dit dui op die Jebusitiese vesting wat deur Dawid verower is. Dit was hy wat die naam "vesting van Sion" verander het tot "stad van 
Dawid" (2 Sam 5:7, 9). Volgens alle waarskynlikheid is deur die gebruik van die naam Sion die Ofelrif in die suidoostelike deel van Jerusalem bedoel.

Toe die omtrek van die stad uitgebrei is deur Salomo, seun van Dawid, is die hoogte warop die tempel gebou is, Sion genoem. Die Siontradisies word gewoonlik verbind aan die tempel waar God teenwoordig is. Al sou die hele stad nog Sion genoem kon word, is die gebruik van die naam afgestem op die tempelberg. Dit sou primêr Sion aandui in latere teologiese interpretasies.

Die naam Sion is ook gebruik om die hele stad Jerusalem met al sy mense aan te dui. Veral in poëtiese gedeeltes is Sion deur Jerusalem vervang (Ps 51:18; 76:2; 102:21). Volgens Hebreeuse gebruik is Sion/Jerusalem dikwels in die literatuur verpersoonlik as ' $n$ jong vrou (Ps 9:14; Jer 4:31).

In die vroeë Christelike era is die term Sion gebruik om die suidwestelike heuwelgebied van Jerusalem aan te dui. Dit hang moontlik saam met Herodes se rekonstruksie van die stad waarvolgens die suidwestelike heuwelgebied die belangrikste deel geword het. Die huidig gangbare interpretasie om die heuwel waarop Dawid se graf en die bo-vertrek, waar Jesus die nagmaal ingestel het, aangetref word, Sion te noem, is eintlik Bisantyns van oorsprong en nie die berg Sion waarna in Bybelse tradisies verwys word nie. Die Bybelse berg Sion is die tempelberg waar die moskee vandag pryk.

Die betekenis van die Bybelse term Sion lê egter nie op die gebied van topografie nie, maar van die teologie. Die bedoeling is nie om die sogenaamde eskatologie van elke Ou- en Nuwe-Testamentiese Bybelboek te beskryf nie of om die voorkoms van Sion in elke Bybelboek na te gaan nie, maar om eerder die teologie van die eskatologiese tradisies rakende Sion, soos Israel dit beleef het, na te gaan. Die term Sion ontlok teologies 'n verskeidenheid betekenisse soos God se koningskap en mag, sy geregtigheid, sy trou, versorging en sekuriteit. Diegene wat sy berg Sion betree, geniet God se troue beskerming. Die Siontradisies kom veral prominent in die Psalms en Jesaja voor ${ }^{6}$.

Psalm 48 kan as 'n algemene verteenwoordigende Sionpsalm beskou word. Sion is die plek waar God se geloofwaardigheid en onoorwinlikheid gelokaliseer is. Dit is ook die plek waar Hy besing moet word. By Sion kom woord en antwoord by mekaar uit. God se heerskappy word deur lofprysing beantwoord. Die koningskap wat volgens Psalm 48 besing word is dié van die Here alhoewel in gedagte gehou moet word dat volgens die Jerusalemteologie ook Dawid bedoel kon wees?. Die koningskap van die 
Here en sy gekose regeerder en aangenome seun Dawid is vervleg. Die heerskappy berus volgens tradisie op 'n oorwinning wat die koning se mag en heerskappy uitbeeld. Sion is die plek waar die oorwinning gesien word (Ps 48:9). Daar vind die teofanie plaas. Die jubelendes, wat moontlik 'n groep pelgrims is, moet rondom Sion trek en die torings, mure en versterkings sien (Ps 48:13-14). Blydskap oor die oorwinning en troonbestyging van die koning laat Sion jubel. Die troonbestyging is volgens tradisie gekenmerk deur feestelikheid. Die volle deurbraak van die Here se heerskappy is 'n eskatologiese gebeure wat siklies deur die geskiedenis heen op Sionsberg gevier word. Die troonbestyging van die Here simboliseer teologies sy meesterskap oor almal en alles, asook sy beheer oor die natuur. Op Sion kom skepping en verlossing bymekaar. Alhoewel die Siontradisies en die Eksodustradisies nie saamval nie, beteken dit nie dat hulle teenoor mekaar staan nie. Die Here se versorgende heerskappy en verlossing vul mekaar eerder aan by wyse van teologiese interpretasies.

Nog 'n opvallende uniekheid wat aan Sion gekoppel word is die van verkiesing. Die Here het dit gekies om die plek van koninklike heerskappy te wees waar sy tempel setel. Die plek waar sowel Hy as sy onderdane rus vind". Die verkiesing van Sion kan moontlik verstaan word binne kultiese verband wat saamhang met die deuteronomistiese kultussentralisasie van Sion. Jerusalem is daarvolgens die uitverkore plek van die Here ${ }^{10}$. Dit is egter waarskynliker dat die verkiesing van Sion saamhang met die tradisie dat die huis van Dawid vir koningskap bestem is. Die Dawidiese teologie bied 'n waarskynliker raamwerk vir die Siontradisies"'. Psalm 2 dien as 'n duidelike voorbeeld. Dawid is die Here se gevolmagtigde verteenwoordiger wat die vyandige magte moet oorwin.

'n Verdere gevolg van die oorwinning van die Here by Sion is die aanbreek van vrede. Die aanvaarding en erkenning van die Here se triomf is die basis van die universele vrede wat aanbreek. Ons lees in Jesaja 2:2-4 dat Sion bokant al die ander berge uitsteek en dat die nasies daarheen stroom. Uit Sion kom die bekendmaking van die Here se wil; uit Jerusalem kom die woord van die Here. Sion is die gelokaliseerde bron van die onderwysing (Tora) van die Here. In plaas van oorlog, lees ons van die suksesvolle onderhandelinge tussen die nasies wanneer die swaarde ploegskare word en die spiese snoeiskère (Jes 2:4). Dit is deur erkenning van die Here se onoorwinlikheid, versimboliseerd in die Sionsberg, dat die oorlogsugtige nasies vrede maak. Daarom word die Sionsberg eskatologies verheerlik. Baie wil hulle lewe daar deurbring (Ps 23:6; 27:4). Sommige eksegete beskou Sion selfs as plek van asiel12.

Enkele opmerkings oor die Siontradisies gedurende die monargie en die tweede tempelperiode bied verdere reliëf op Sion as sodanig. Met 
Dawid se verowering van Jerusalem en sy troonbestyging van die verenigde koninkryke van Juda en Israel, asook as gevolg van die tempel wat Salomo gebou het, het die Siontradisies 'n wesenlike deel geword van Israel se godsdienstradisies. Die gedeeltelike vervlegting van die Dawiden Siontradisies moet waarskynlik gedurende die periode gesoek word. Sion het ontstaan as simbool van Israel se opvatting dat die hoë berg die koning se setel is van waar hy regeer en oor die vyande heers. As koninklike heiligdom van die verenigde monargie, maar ook van Juda na die skeuring, het Sion 'n pelgrimsoord geword (Ps 84; 122). Dit sou selfs nog belangriker word toe Hiskia en Josia gepoog het om die Jerusalem as sentrale offersentrum te vestig ${ }^{13}$.

Die Siontradisies is veral deur die profeet Jesaja uitgebou. Sommige meen egter dat die Siontradisies in Jesaja 'n latere interpolasie is ${ }^{14}$. Dit hoef egter nie sover gevoer te word nie omdat die Siontradisies goed inpas by die algemene Jesajateologie en -wêreldsiening.

$\mathrm{Na}$ die val van Juda en die tempel in $587 \mathrm{vC}$ het Sion 'n simbool van skande geword omdat die bestaande ruïnes afgesteek het teen die eens magtige koninklike stad en vesting. Dit is eers weer herstel volgens TritoJesaja se teologiese interpretasies.

Veral Sagaria het die Siontradisies aangewend in die periode van herstel na die ballingskap. Daarvolgens het God sy liefde vir Sion herbevestig. Die dag van oordeel word daar gelokaliseer (Sag 1:15,20,21; $2: 7-9 ; 6: 1-8$ ), want die Here is nog jaloers in sy liefde vir Jerusalem (Sag $1: 14,16,17)$. Die nasies sal na Sion kom om die Here te aanbid (Sag 2:1013; 8:20-23). Sagaria 8:3 vat dit só saam: "So sê die Here: Ek gaan na Sion toe terugkom, Ek gaan in Jerusalem woon". Verder word gesê dat Jerusalem die "Stad van Trou" genoem sal word, "Berg van die Here, die Almagtige, Heilige Berg" (Sag 8:3).

In die buite-Bybelse literatuur word Sion as parallelle term vir die geografiese Jerusalem gebruik's. Algaande is egter ook 'n groter apokaliptiese en eskatologiese betekenis aan Sion gekoppel, veral in die literatuur wat ná die verwoesting van Jerusalem ontstaan het. Die gebeure in $70 \mathrm{nC}$ het 'n eskatologiese herformulering van die Siontradisies tot gevolg gehad $^{16}$. Verwagtinge van historiese verwerkliking van ideale het nou plek gemaak vir toekomsprojeksies oor die verwagte stad van God wat onwankelbaar sou wees op die dag van oordeel. Slegs na die transformasie van die skepping sou Sion herbou kon word (2 Bar 22-32). Die verwoeste aardse Jerusalem kon nie meer die verwagte stad van God wees nie. Dit moet plek maak vir die eskatologiese, eintlik apokaliptiese, hemelse Sion (2 Bar 4; 68; 69). 
Gedurende die Rabbynse en Christelike periodes het die fokus veral op die vergeesteliking van die hemelse Jerusalem geval teenoor die aardse Jerusalem wat geassosieer is met die Jode en slawerny. Die oortuiging het nog sterk geleef dat Jerusalem (Sion) 'n prominente plek inneem in die eskatologiese verwagtinge, al is dit in 'n vergeestelikte sin.

Die Hebreërskrywer is verteenwoordigend van die Nuwe-Testamentiese opvattinge. Van Abraham word byvoorbeeld gesê dat hy "uitgesien het na die stad wat vaste fondamente het en waarvan God self die ontwerper en bouer is" (11:10). Die heiliges van die Ou Testament het uitgesien "na 'n beter vaderland, dit is die hemelse" (Heb 11:16). Aan hulle verwagtinge is egter nie voldoen soos wat hulle dit verwag het nie omdat God "iets beters beoog het..." (Heb 11:39). Die Christelike kerk beleef nou wat die gelowiges van die Ou Testament net verwag het, naamlik toegang tot God in die heilige stad, dit is "Sionsberg en die stad van die lewende God, dit is die hemelse Jerusalem..." (Heb 12:22). Die aardse Sion was maar 'n afskynsel van die hemelse model en werklikheid. Die aardse Sion is soos 'n slawevrou, maar die hemelse Sion is vry en die moeder van sowel die Jode as heidene (Gal 4:21-27). In Jesus Christus kulmineer die Sionsverwagtinge. Wat Sion moes bied, omdat die aardse Sion gefaal het, is nou volledig te vind in Jesus Christus. En tog het die eskatologiese verwagting van die hemelse Jerusalem wat van God af kom, uit die hemel uit, sterk geleef (Op 21:2). Dit is 'n stad op 'n hoë berg (Op $21: 10$ ) met 'n rivier van lewe wat daaruit vloei (Op 22:1,2). Dit is verder opvallend dat die tempel daarin ontbreek (Op 21:22). Die stad word soos 'n kubus voorgestel $(\mathrm{Op} 21: 15,16)$, verwysend na die vorm van die allerheiligste in die tabernakel, en simbolies van die Goddelike teenwoordigheid. Dié teenwoordigheid van die Lam gee aan Sion nuwe betekenis wat eskatologiese uitsig bring vir die Christelike kerk.

\section{ESKATOLOGIESE SION}

Israel se geloof rakende Sion moet nie net geografies of histories verstaan word nie, maar ook eskatologies.

Enkele tersaaklike opmerkings na aanleiding van die Ou Testament in dié verband werp lig op die eksegetiese verstaan van Nuwe-Testamentiese eskatologiese tekste, soos byvoorbeeld Openbaring 14:1.

Die aanspraak is eenmaal gemaak dat die hele Ou Testament "the epos of the fall of Jerusalem" is ${ }^{17}$. Dit mag ' $n$ oordrywing wees, maar Sion neem 'n prominente plek in die teologiese denke van Israel in. Die interessante vraag bly staan waarom die stad op die heuwel so 'n dominante rol in 
Israel se eskatologiese denke speel. Die uiteindelike verheerliking van Sion affekteer alle ander aspekte van Ou-Testamentiese eskatologie.

'n Noukeuriger kyk na Sagaria 8 as vertrekpunt bied 'n invalspoort tot die dieper verstaan van die Ou-Testamentiese eskatologie. In Sagaria 8 kom die verlede, hede en toekoms van Sion ter sprake. Die heropbou van Jerusalem is aan die gang nadat sommige bannelinge teruggekeer het. Aanbidding vind weer plaas op die heilige berg Sion. Sommige aanbidders kom na Sagaria toe om uitsluitsel te kry of hulle nog moet vas oor die wegvoering, terwyl die restorasie reeds aan die gang is (Sag 7). Sagaria wys die volk op alles wat God reeds in hulle geskiedenis gedoen het en nog gaan doen, asook wat hulle gedoen het en nog behoort te doen. Die volk word daaraan herinner dat die wegvoering in ballingskap die gevolg van hulle sonde was (Sag 7:7,11-12). In Sagaria 8:1 begin die profeet bou aan 'n eskatologie wat "gereduseerd" en "futuristiese" trekke bevat ${ }^{18}$. Wat die profeet sê, word met Sion in verband gebring. Die Here "is hartstogtelik begaan om Sion" en Hy "gaan na Sion toe terugkom" (Sag 8:2-3). Sion word as eskatologiese simbool voorgehou wat verlede, hede en toekoms omsluit. Dit sluit aan by die verwagtinge van die "nuwe Jerusalem". God se volk sal herstel word in die beloofde land (Sag 8:7-8). Slegs Jerusalem/Sion word as deel van die beloofde land vermeld. Die tipiese verbondsformule: "Hulle sal my volk wees en Ek sal hulle God wees", dien as eskatologiese drakrag (Sag 8:8). Die nasies sal nie langer spot nie, maar vrywillig na Jerusalem toe kom om die wil van die Here te soek (Sag 8:21). Die eskatologiese speerpunt lê daarin dat Sion weer die "Stad van Trou" (Sag 8:3) sal wees waar die waarheid en die reg geld, vrede en geen valse ede nie (Sag 8:16-17). Bejaardes en jonges sal in Sion sekuriteit en vrede geniet en fees vier (Sag 8:4-5). Die bron van sekuriteit is God se teenwoordigheid in Sion.

In die geskiedenis van Israel se eskatologiese denke het Jerusalem en Sion relatief laat op die toneel verskyn. Dit is nie prominent geassosieer met die patriarge nie; eerder Sigem, Betel, Hebron en Berseba' ${ }^{19}$. Eers vanaf Dawid se tyd het Jerusalem as aanbiddingsplek in fokus gekom, toe die ark na daardie gebied gebring is (2 Sam 7). Van toe af is koningsheerskappy en eskatologiese denke vervleg. God het Sion as sy vesting en rusplek gekies. Die koningskapsmotief is verder uitgebou toe Salomo die tempel gebou het vir die ark (1 Kon 6-8). Die agtste-eeuse profete Miga en Jesaja se woorde oor Jerusalem (positief en negatief), asook Josia se sewende-eeuse wetshervormings benadruk dat Sion die aanbiddingsplek van die Here is (1 Kon 12:25-33; 2 Kon 17). So ook in die psalms van Sion en die pelgrimsliedere (Ps 84,122). En ná Jeremia en Esegiël se aanvalle 
teen die tempelteologie, val die vesting in $587 \mathrm{vC}$. Die plek van hoop het nou 'n simbool van vernedering geword. Daarom het Jeremia en Esegiël ook gepraat van 'n nuwe Jerusalem wat deur God self opgerig sal word. In die "seerkry" van die Sionteologie met die val van Jerusalem lê ook die geboorte van 'n Sioneskatologie waarvolgens Israel sy teologiese hande uitsteek na God toe vir die toekoms. Sion as eskatologiese simbool bly dus prominent ${ }^{20}$.

'n Opname van Ou-Testamentiese eskatologiese temas toon aan dat Sion die tipiese saambindende element in Israel se teologiese denke is ${ }^{21}$. Gowan onderskei drie eskatologiese temas, naamlik die transformasie van die gemeenskap, die transformasie van die mens en die transformasie van die natuur ${ }^{22}$. Die transformasie van die gemeenskap behels die herstel van die beloofde land, die regverdige koning en oorwinning oor en vrede met die nasies. En by die transformasie van die individuele mens kom ter sprake: eskatologiese vergifnis, die bedoeling met herskepping en die nuwe mens. By die transformasie van die natuur val die klem op oorvloedige vrugbaarheid, 'n nuwe orde en 'n nuwe aarde. Samevattend sou 'n mens kon sê dat Israel sy denke om die toekoms en sy verwagtinge in terme van Sion uitgedruk het.

Om terug te keer na die beloofde land toe, beteken om na Jerusalem terug te keer: "Ek gaan 'n nuwe hemel en 'n nuwe aarde skep... Ek gaan 'n Jerusalem skep wat vol blydskap is..." (Jes 65:17-18). Is dit nie by wyse van spreke, opwindend dat Sionsberg wat nie eers só hoog soos die Olyfberg is nie, die hoogste berg op aarde word nie (Jes 2:2)! Dit is 'n teologiese en nie 'n topografiese "hoogtepunt" in Israel se eskatologiese denke nie. Dit moet ook formeel in verband gebring word met die mitologie van die antieke Ooste waar die sogenaamde wêreldberg die hoogste was - die sentrum van die aarde waar God ook te vinde is ${ }^{23}$. Die hoogte word beklemtoon omdat dit die plek is waar hemel en aarde aan mekaar raak. God is daar teenwoordig. Binne só 'n eietydse denkraamwerk is die beklemtoning van Sion vanuit Bybelse perspektief nog beter verstaanbaar.

Die vervlegtheid van die koningskaps- en eskatologiese motief met Sion kom baie duidelik na vore in Jesaja 33:17-24 waar 'n omvattende prentjie geteken word van die nuwe era. Die koningskap van die Here word verwag (Jes 33:22). Dit is egter moontlik dat die koning, na wie verwys word in Jesaja 33:17, 'n aardse koning van die toekoms is wat later die Messias genoem sou word24. Die stad bied 'n vesting van sekuriteit. Die inwoners is vergewe (Jes 33:24). Jesaja 33:17-24 kontrasteer die tye van bedreiging met die tyd van sekuriteit wat sal aanbreek; die tye van siekwees met die totale vergifnis wat kom. Sion sal in vrede gehul wees. 
Prominente tekste wat handel oor die hele proses van herstel is Jesaja 49:14-26 en Sefanja 3:14-15. Sion het die simbool van die ware volk van God geword. Sion word metafories as die moeder van Israel geteken (Jes 49:20). Die terugkerendes uit ballingskap is "haar" seuns en dogters. Die intieme verhouding tussen God en die stad is 'n voorskou van die verhouding tussen God en sy eie mense wat moet kom. Nog eens word beklemtoon dat Israel se teologiese denke oor die eskatologiese hoofsaaklik deur die transformasie van die mense, gemeenskap en natuur gedefinieer word. Dieselfde wesenlike van Ou-Testamentiese eskatologie, naamlik die herstel van wat verkeerd gegaan het met mens en wêreld, word in Sefanja 3:14-16 besing. Vrees en rampe het plek gemaak vir blydskap en feesviering. Die "Koning van Israel, die Here" is by sy mense (Sef 3:15). Die Siontema het vanuit die kultiese sfeer die eskatologiese betree deurdat die Here, die koning, op Sion teenwoordig is. Sion het die oord geword van waaruit alle seëninge vir hede en toekoms vloei. Dit is die sentrum van die menslike bestemming.

Gedurende die periode $200 \mathrm{vC}-200 \mathrm{nC}$ waartydens die apokriewe en pseudepigrafiese geskrifte meestal ontstaan het, neem Jerusalem steeds 'n sentrale plek in die eskatologiese denke in. Die skok van die vernietiging van Jerusalem in $70 \mathrm{nC}$ word op verskeie maniere verwerk en beskryf. Sonder om die herstel van die aardse Jerusalem op te gee, kom veral by 4 Bsra en 2 Apokalips van Barug 'n nuwe element by, naamlik die verwysing na die hemelse stad wat sedert die skepping reeds bestaan het. Volgens 4 Esra sien Esra 'n groot stad (4 Esra 9:38-10:27). Die boek Openbaring sluit hierby aan (Op 21-22). Die transendente Jerusalem, volgens die literatuur, word nou die hoogste bestemming nadat die aardse Jerusalem eenmaal gefaal het. Die siener volgens 2 Henog 55:2, 'n laat apokalips, gaan sover om te sé dat hy die volgende dag "na die hoogste Jerusalem gaan, na sy ewige erfenis". Veral in die christelike geskrifte is die uitsien na die herstel van die aardse Jerusalem verplaas deur 'n hoop op die hemelse Jerusalem. Dit was nie die geval in Judaïsme wat bly hoop het op die herstel van die aardse Jerusalem nie2s. Twee van die agtien Sinagoge-gebede (14 en 17) was juis vir die herstel van Jerusalem. Later sou die christelike kruistogte ook die sentraliteit van Sion/Jerusalem beklemtoon.

Justinus en Tertullianus praat van die hemelse stad wat uit die hemel neerdaal gedurende die millennium ${ }^{26}$.

'n Ander christelike tendens rakende Jerusalem het ontwikkel: die hemelse Jerusalem is met die kerk geïdentifiseer, veral by Origines, Augustinus en Eusebius ${ }^{27}$. Die nuwe Jerusalem word ook met die hemel 
vergelyk. Saamgesteld beskou, word die nuwe Jerusalem beskou as die koms van God se koninkryk op aarde, alreeds teenwoordig in sy embrionale vorm, die kerk. Die herstel van die fisiese, aardse Jerusalem speel 'n minimale rol in die christelike eskatologiese denke in vergelyking met dié van die Judaïsme. Hoe dit ook al verskil, die nuwe Sion bring transformasie vir gemeenskap, individu en natuur.

\section{DIE NUWE JERUSALEM VOLGENS OPENBARING}

In die boek Openbaring is sprake van twee Jerusalems: die nuwe Jerusalem wat van die hemel af kom as deel van die nuwe skepping, asook die "heilige stad" van Openbaring 11:2. Eersgenoemde is die bruid en vrou van die Lam (Op 19:7; 21:2,9), die stad van God (Op 3:12), die heilige stad Jerusalem (Op 21:2) en toon opvallende ooreenkomste met die OuTestamentiese Siontradisies. Laasgenoemde Jerusalem, volgens Openbaring 11:2 is nie die aardse Jerusalem nie, maar waarskynlik 'n rëinterpretasie van die profesieë van Daniel oor die ontheiliging van die tempel (Dan 8:9-14; 11:31; 12:11). Dié tradisies word herinterpreteer om te verwys na die vervolging van die kerk vir drie-en-'n-half jaar in konflik met die Romeinse owerheid. Die "heilige stad" wat deur die heidene vertrap word, is die kerk in vervolging. Die hemelse vrou volgens Openbaring 12:1-6 en 13-17 val ook in dié kategorie.

Die nuwe Jerusalem van die toekoms (Op 21), die bruid van die Lam, het sowel 'n voorloper as 'n teëhanger in die hede. Die voorloper is die heilige stad Sion en die teëhanger is Babilon, die ontugtige. Terwyl Babilon reeds sigbaar regeer oor die konings van die aarde (Op 17:18) is die nuwe Jerusalem van die toekoms nog verborge en funksioneer in die narratief van Openbaring as die kontradiksie waarna uitgesien word omdat dit universeel heerskappy sal voer. Op só 'n wyse is die Siontradisie as plek van waaruit God regeer in die nuwe Jerusalem-verwagtinge opgeneem.

Dit is só tipies van die narratief in Openbaring om die lesers te betrek in ' $n$ simboliese universum wat weer op sy beurt insig gee ten opsigte van die hede. Indien die lesers moet dissosieer van Babilon met "haar" verderwende invloede en pretensies, moet die teenbeeld in die simboliese universum geskep word waarmee hulle kan assosieer. Dit sal ook hul eskatologiese denke dominant moet bepaal. Wat anders pas so goed in by dié scenario as God se alternatiewe stad van die toekoms - die nuwe Jerusalem. Al is dié stad deel van die toekoms, dra die verwagtinge daarvan die lesers reeds gedurende die hede. Dit neem die sentrale posisie 
in alle eskatologiese denke in - dieselfde rol as wat Sion in die OuTestamentiese eskatologiese denke gespeel het.

Die nuwe Jerusalem is op ' $n$ hoe berg (Op 21:10) en straal die heerlikheid van God uit. Die lesers kan nie nou reeds toegang tot dié stad kry nie, maar alreeds 'n plekkie antisipeer (Op 3:12; 22:14,19) omdat hulle in die simboliese universum alreeds deel is van die bruid van die Lam (Op 19:7-8; 22:17). Die nuwe Jerusalem as bruid van die Lam waarvan die lesers hulself alreeds as deel mag beskou funksioneer dus dinamies en funksioneel in die denke van die lesers (Op 21:9-22:9). Dit opponeer die sondige Babilon (Op 17:1-19:10) in die klimaksgedeelte van die narratief van Openbaring. Babilon verteenwoordig én oortref die Ou-Testamentiese Babel, Egipte, Sodom, Tirus en Edom ${ }^{28}$. Eers wanneer die kulminasie van gruwel en sonde (Babilon) tot 'n val kom, kan die nuwe Jerusalem in volmaakte glorie verskyn as ewige tuiste van die gelowiges omdat God daarin teenwoordig is en regeer. As plek is die nuwe Jerusalem tegelyk paradys, heilige stad en tempel. As paradys verteenwoordig dit die herstel van die natururlike orde in sy ideale staat waar die teenwoordigheid van God volmaak is. As heilige stad is dit die vervulling van die ideale plek waar hemel en aarde ontmoet en vanwaar God sy eie mense regeer, maar ook waarheen die nasies stroom om in dié nuwe teosentriese gemeenskap vrede en rus te vind. As stad is die nuwe Jerusalem die setel van die heerskappy van die Here (Op 22;1,3). Dit is die sentrum van lig waarheen die nasies en hulle konings kom, soos na Sion toe (Op 21:24; Jes 60:3,417; Sag 14:16). Die bron van koningskap en heerskappy setel in Sion - die nuwe Jerusalem. Die hele stad is vol van God se heilige teenwoordigheid. Dit is sy "heilige berg" (Sag 14).

Die geskjedenis van Israel sowel as die christelike kerk kom tot vervulling in die nuwe Jerusalem. Die name van die twaalf stamme van Israel is op sy hekke (Op 21:12), net soos in Esegiel se visioen (Eseg 48:30-34). En die name van die twaalf apostels is op sy fondamente (Op $21: 14)$.

Die klimaks van die vertelling van die nuwe Jerusalem is ongetwyfeld dat die bestemming van die lesers is om God as koning te dien (Op 22:3-5). Dit is om werklik "n koninkryk en priesters van ons God" (Op 5:10) te wees. Om te deel in God se koningskap deur self as heersers namens Hom op te tree (Op 22:5). Die fokus op die universele verlossing moet nie misgekyk word nie. Net soos wat God sorg vir sy eie in die nuwe Jerusalem, die verbondskinders, so word daarin ook die Ou-Testamentiese profesieë vervul dat die heidense nasies en konings ook deur sy hekke beweeg (Op 21:24-26). Dit beteken egter nie individu vir individu nie. 
God se skepping bereik sy eskatologiese vervulling in die nuwe Jerusalem wanneer God direk, volmaak en vir ewig teenwoordig is by sy mense. Eers was Hy sittende op die troon (Op 4-5) of slegs toeganklik in die binneste heiligdom (Op 11:1-2; 13:6), maar in die nuwe Jerusalem is Hy onmiddellik beskikbaar tussen die mense (Op 21:3) en vervang sy teenwoordigheid die noodsaaklikheid van die fisiese tempel.

Wanneer God op sy troon sit in die nuwe Sion, is daar nie meer bemiddelaars nodig tussen Hom en die mense soos in Openbaring 4-5 nie maar het elkeen direkte toegang om saam met God en die Koning van alle konings te heers (Op 22:3-5). Op só 'n wyse vind die gelowige sy/haar volmaakte bestemming of outonomie in die volmaakte eskatologiese teonomie van God, die Koning.

\section{NOTAS:}

1 Vergelyk E Nestle \& K Aland, Novum Testamentum Graece, Stuttgart 261988.

2 Vir volledige eksegese, vergelyk R H Mounce, The Book of Revelation, Grand Rapids 1977, 266-271; M E Boring, Revelation, Louisville 1989, 168-172.

3 Vergelyk 2 Esra 2:42-47. Volgens 2 Esra 13 het die Jode 'n Messias verwag wat op die berg Sion met ' $n$ groot skare vergader.

4 Joël 2:32 vermeld dat diegene op Sionsberg die groot en vreeslike "dag van die Here" sal vryspring.

$5 \quad$ Kyk W A Elwell (ed), Baker Encyclopedia of the Bible, Grand Rapids 1988, 2200-2203; H Balz, G Schneider (eds), Exegetical Dictionary of the New Testament, Vol 2, Grand Rapids 1981, 176-179; D N Freedman (ed), The Anchor Bible Dictionary, Vol 6, New York 1992, 1098-1102.

6 Vergelyk byvoorbeeld Psalms 2,46,48,65,76,84,87,95-99,110,122,125,128, 132; Jesaja 8:5-10; 17:12-14; 24:21-23; 25:6-12; 26:1-7; 30:27-33; 33:5-6, 14:24; 37:33-38, 60-62; 65:17-25. Kyk W S Prinsloo, Psalm 87: "Jahwe het Sion uitverkies, maar die vreemde volkere behoort ook aan Hom", NGTT 32/4 (1991), 522-530.

$7 \quad$ Kyk J D Levenson, Zion Traditions, in: D N Freedman, $a$ w, 1099.

8 Vergelyk J D Levenson, Sinai and Zion: An entry into the Jewish Bible, San Francisco 1987, 185-217.

9 Kyk Psalms 78:68-69; 132:13; vergelyk 1 Kon 8;44,48; 11:13,32,36; 14:21; 2 Konings 21:7; 23:27; Sag 1:17; 2:16; 3:2. 
10 Vergelyk B Ollenburger, Zion: The city of the great king, Sheffield 1987, 61.

11 Kyk J J M Roberts, The Davidic origin of the Zion tradition, JBL 92 (1973), 329-344.

12 L Delekat, Asylic und Schutzorakel am Zionheiligtum, Leiden 1967, 166-176 is van mening dat Sion by uitnemendheid ' $n$ heilige plek is waar asiel gevind kan word en haal die volgende tekste aan: Eksodus 21:12-14; Numeri 35:9-34; Deuteronium 19:1-12; 1 Konings 1:50-53; 2:28-35.

13 Vergelyk 2 Kronieke 30; 2 Konings 23:1-27. Kyk J D Levenson, a w, 1102.

14 Kyk R E Clements, Isaiah and the deliverance of Jerusalem, Sheffield 1980, 72-89.

15 Vergelyk 1 Markus 4:37; 5:54; 10:11; 2 Makkabeērs 7:1; 10:7-12; $13: 1$.

16 Elwell, $a w, 2203$.

17 J C Todd, Politics and religion in Ancient Israel, New York 1904. Vergelyk die beoordeling van dié standpunt deur R $\mathrm{H}$ Charles, Eschatology: The doctrine of a future life in Israel, New York 21963, en J Klausner, The messianic idea in Israel, New York 1955.

18 Kyk D E Gowan, Eschatology in the Old Testament, Philadelphia 1986, 4-20.

19 Die berg Moria (Gen 22) word met Jerusalem in verband gebring (vgl 2 Kron 3:1) maar dié identifisering is onseker, vergelyk D E Gowan, a w, 8.

20 Alhoewel die noordelike profete Amos en Hosea melding maak van Dawid (Hos 3:5; Amos 9:11-12) word niks oor Sion gerep nie. Die agtste eeuse Judese profete Miga en Jesaja se boodskappe is vervleg met aanhalings oor Sion: ongeveer twintig voorkomste in Jesaja 1-39. Sion word ook vermeld in Sefanja 3:14-20; vyf keer in Jeremia $(3: 14 ; 30: 18-22 ; 31: 6: 31: 10-14 ; 31: 23$ ) en agt keer in die prosagedeeltes van Jeremia $(3: 15-18 ; 27: 22 ; 29: 10-14 ; 31: 38-40$; $32: 36-41,44 ; 33: 4-9,10-11,12-13,14-16 ; 50: 4-5)$. Sion kom twaalf keer voor in Deutero-Jesaja, elf keer in Trito-Jesaja en agt keer in Sagaria (1:14-17; 2:1-12; $3: 2 ; 8: 1-23 ; 9: 9-10 ; 12: 1-9 ; 13: 1 ; 14: 1-21)$. Vergelyk Gowan, $a w, 9$ en 131.

21 Kyk Gowan, $a w, 12-19$.

$22 A w, 10$.

23 Kyk R L Cohn, The shape of sacred space, Chico 1981, 25-42.

24 Vergelyk O Kaiser, Isaiah 13-39, Philadelphia 1974, 347. Vergelyk R E Clements, Isaiah I-39, Grand Rapids 1980, 269. 
$25 \quad$ Vergelyk Gowan, $a w, 18$.

26 Kyk Justinus: Dialogue with Trypho, 119:5 en Tertullianus: Against Marcion III, 24:3-4.

27 Origines: Homily on Jeremiah 11:1; Augustinus: City of God 8:24; Eusebius: Ecclesiastical History X:4, 7.

28 R E Bauckham, The theology of the book of Revelation, Cambridge 1993, 131 tabuleer die parallelle tussen Jerusalem en Babilon vollediger. 